\title{
Sobre um caso de meningo-myelite syphilitica
}

\author{
Observação feita na Clinica Neuro. \\ Iogica da Faculdade de Medicina \\ pelo doutorando Pedro Filizola.
}

J. P. - com 56 annos de idade, italiano, casado, lavrador, côr branca, natural de Udine e procedente de Chavantes. Entrado em 21 de Março de 1927.

\section{ANTECEDENTES HEREDITARIOS}

Paes fallecidos na Europa de causa ignorada. Tinha duas irmãs, das quaes uma falleceu com meningite-cerebro-espinhal; em relação á outra nada informa. Sua mulher gosa de relativa saude. Tem seis filhos todos vivos e fortes. Nega que sua mulher tenha tido abortos.

\section{ANTECEDENTES PESSOAES}

Em sua infancia, afóra o sarampo e coqueluche, sempre teve boa saude. Quando tinha doze annos, teve maleita que durou acerca de um mez. Na Allemanha, onde trabalhou acerca de dois annos como mineiro, soffreu um accidente, do qual resultou fractura do terço inferior do femur do lado direito, e uma incisão na face dorsal da mão em correspondencia ao ultimo metacarpiano.

Apresenta tambem na phalangeta do dedo indicador direito uma cicatriz, proveniente tambem de um accidente. Perdeu por isso os movimentos dessa mesma phalangeta.

O paciente diz ter soffrido um processo inflammatorio no globo occular direito que cedeu apóz alguns dias pela applicação de compressas humidas. Resultou uma perda parcial da visão dessa mesma vista. Nega qualquer antecedente venereo ou syphilitico. Era alcoolatra. E' tabagista. 


\section{MOLESTIA ACTUAL}

Sua molestia iniciou-se ha 8 (oito) mezes. Sentiu nesse começo, que as partes mais distaes dos membros superiores, eram séde de sensações diversas, taes como formigamento, picadas, mais accentuadas do lado esquerdo que do lado direito. Declara o doente, que esses phenomenos tiveram como ponto de partida os dedos de ambas as mãos e que pouco a pouco, essas mesmas sensações encaminharam-se para as raizes dos membros.

Submetteu-se a um tratamento, em Chavantes, não conseguindo melhoras (19 injecções). Tempos depois identicas sensações manifestaram-se nos membros inferiores, começando tambem pelas extremidades distaes. Por essa mesma epoca, começou a notar que a sua marcha tornava-se difficil; sentiu uma extrema debilidade nos membros inferiores, de modo a não permittir que se entregasse aos seus affazeres diarios. Notava tambem, que suas mãos, bem como os seus ante-braços estavam se tornando emmagrecidos, perdendo a força muscular, facto esse mais accentuado á esquerda. Nessas condições deu entrada neste hospital.

\section{EXAME DO SYSTEMA NERVOSO}

ESTATICA. EQUILIBRIO. - O doente acha-se acamado. Sua posição mais commum é a de decubito dorsal. A mudança dessa posição para a de decubito lateral, é feita com grande esforço, e com auxilio de outra pessoa, não permanecendo nessa attitude durante muito tempo.

NOÇÃO DA POSIÇÃo SEgMENTAR: - Acha-se presente e normal. Signal de Romberg: prejudicado pela sua impossibilidade de permanecer em estatica bipede, com os pés unidos.

TONUS MUSCULAR: - Apresenta-se augmentado nos membros inferiores; nos superiores mostra-se tambem augmentado, porém em menor gráu que nos inferiores.

MARCHA: - O doente acha-se quasi impossibilitado de andar, e quando o faz, procura sempre pontos de sustentação com as mãos. A marcha tem os caracteres de espasticidade, com augmento da base de sustentação, pelo afastamento dos membros inferiores. Na marcha, quando o pé direito se acha collocado posteriormente ao esquerdo, executa um movimento de rotação do calcanhar para dentro.

FORÇA MUSCULAR: - Nulla ou quasi nulla á esquerda; bastante diminuida á direita (membros superiores).

PARAlYSIA: - Membros inferiores paralysados; paralysia mais pronunciada á esquerda. Não apresenta phenomenos cerebellares. Paresia da corda vocal esquerda (Dr. Paulo Saes). 
Examinando-se a uvula quando o doente emite a vogal $A$ vê-se que a retracção não é uniforme, mas ha um pequeno desvio para á esquerda.

TREMORES FIBRILLARES: - Nos musculos triceps brachial, deltoide, grande peitoral de ambos os membros, pela percussão verificam-se tremores fibrillares. $\mathrm{Na}$ lingua os mesmos tremores se manifestam expontaneamente. Nos membros inferiores os tremores se localisam nos musculos gemeos.

SENSIBILIDADE GERAL SUbuJectiva: - Dores continuas em cinta, abraçando a parte inferior do thorax e do abdomem, com irridiações aos membros inferiores. Sensações de formigamento nos membros superiores e inferiores, a principio mais accentuadas do lado esquerdo, mas agora do lado direito.

SENSIBILIDADE OBJeCtiva superficial: - Perturbações da sensibilidade objectiva superficial sem limites precisos. A' direita tanto na parte anterior como na posterior, desde a extremidade distal do membro inferior até um plano passando pelo bordo superior da segunda costella, sem attingir o membro superior, o doente tem todas as sensibilidades supeficiaes (Tactil, termica e dolorosa) perturbadas, não respondendo com precisão, confundindo frio com calor, tacto com dôr, e localisando mal as impressões sensitivas. A' esquerda as mesmas perturbações são notadas, porem a zona perturbada é menor, abrangendo mais ou menos os territorios innervados por L3, L4, L5 e Sl. Para o lado da sensibildade profunda, ha a notar hyperestesia dos musculos da face posterior dos membros inferiores e superiores.

SENSIBILIDADE ESPECIAL: - Visão do lado direito diminuida, segundo os dados anamnesicos. As outras sensibilidades integras.

REFlexos: - Reflexos tendinosos dos membros inferiores: rotuliano, acchiliano, exaltados. Nos membros superiores; tricipital, bicipital, stylo-radial de ambos os lados, vivos. Reflexos cutaneos abdominaes e cremasterinos abolidos. Reflexo cutaneo plantar em extensão (signal de Babinski), mais accentuado á esquerda.

Reflexos pupillares, á luz, á accomodação e consensual, presentes; normaes á esquerda, lentos a direita. Reflexo naso-palpebral normal. Anisocoria com myose a direita. Ligeira ptose palpebral a direita.

TROPHICIDADE: - Tecido cellular sub-cutaneo e gorduroso notavelmente diminuidos.

Existe notavel gráu de emaciação. Nos membros, superiores existem atrophias muito evidentes nas mãos e ante-braços. Os musculos das emminencias thenar e hypo-thenar estão reduzidos, sendo essas emminencias substituidas por escavações. E' nitida a atrophia dos interosseos, dorsaes e palmares, existindo verdadeiras gotteiras inter-osseas.

Nos dedos ha extensão forçada da primeira phalange sobre os metacarpeanos, com flexão das duas ultimas phalanges sobre a pri- 
meira (mão em garra). Em consequencia da atrephia dos musculos da mão, os movimentos de opposição dos dedos são difficeis ou mesmo impossiveis. Os movimentos delicados, como abotoar, segurar um objecto, são difficeis.

Todas essas perturbações são mais notaveis á esquerda. Nos ante-braços a atrophia attinge principalmente os extensores.

Existem contracções fasciculares obtidas pela percussão nos diversos feixes que constituem o musculo grande peitoral: feixe superior, medio e inferior.

estado mental: - Bom.

Linguagem: - Diminuição da intensidade do som, sendo algumas vezes quasi que inaudivel. A articulação das palavras se faz como normalmente. $O$ doente assobia, assopra, deglute bem. Sua saliva não escorre pelos labios. $\mathrm{O}$ doente chora com muita facilidade.

\section{EXAME GERAL}

Individuo consideravelmente emmagrecido. Ganglios inguinocruraes augmentados. Ganglios epithrocleanos infartados em ambos os lados (grãos de chumbo). Tem tibialgia.

APr. Circulatorio: - Oitenta pulsações por minuto. Pulso cheio e isochrono. Bulhas normaes.

APP RESPIRATORIO: - A' palpação e percussão nada de anormal. Pela ausculta, esiertores dessiminados em ambos os hemi-thorax.

APP. URO-GENITAL: - Impotencia genital. Individuo prostatico: removido por essa causa para a $1 .^{\mathrm{a}}$ enfermaria Cirurgia Homens, no dia 18 de Maio do corrente anno, onde foi operado (talha hypogastrica). Verificou-se fermentação ammonical intra vesical, e augmento da prostata.

APP. Digestivo: - Prisão de ventre que dura de seis a oito dias.

EXAME DE LABORATORIO: - Wassermann no sangue, negativo.

EXAME Do liquido CePHalo-RAchidiano: - A primeira punçãao deu liquido hemorrhagico (dia 25-3-927): Wassermann no liquido, negativo. A segunda punç̧ão em 11-4-927, deu:

Pressão.

Albumina.

Reacção de Pandy

, , Weischbrodt.

". " Nonne

, , Benjoim colloidal.

Exame cytologico

Wassermann
38 deitado

0,50 por litro positiva

positiva

positiva

0000000000000000 (16)

18,8 por mm. cubico

positivo (4 cruzes) 


\section{EXAME ELECTRICO}

Membro superior direito:

Membro superior esquerdo:

\begin{tabular}{|c|c|c|c|}
\hline Deltroide & 5 millamp. & Deltroide & 4 millamp. \\
\hline Biceps & 3 & Biceps & \\
\hline Triceps & 6 & Triceps & $31 / 2$ \\
\hline Extensores & 6 & Extensores & 5 \\
\hline Flexores & 4 & Flexores & 6 \\
\hline Inter-osseos dorsaes & $31 / 2$ & Inter-osseos dorsaes & $31 / 2$ \\
\hline Nervo cubital & $31 / 2$ & Nervo cubital & $21 / 2$ \\
\hline , mediano & 4 & " mediano & \\
\hline , radial & 4 & " radial & $4 \mathrm{I} / 2$ \\
\hline Ponto de Erb & 4 & Ponto de Erb & 3 \\
\hline Tronco facial & $21 / 2$ & Tronco facial & $21 / 2$ \\
\hline Abductor pequeno & 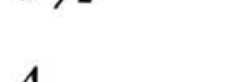 & & \\
\hline
\end{tabular}

\section{DISCUSSÃO}

Em resumo, trata-se de um individuo cuja molestia se iniciou ha oito mezes com formigamentos nos membros superiores, seguidos, pouco tempo depois, de atrophia das mãos e ante-braços.

Ao ser internado neste serviço, ha 3 mezes, além das atrophias acima citadas, notavam-se contracções fibrillares nos musculos do braço e da cintura escapular, além de, impotencia funccional dos membros inferiores com signaes de espasticidade; exaggero de reflexos tendinosos, signal de Babinski, esboço de clonus nos pés. A esse quadro, juntam-se phenomenos bulbares consistentes em tremores fibrillares da lingua, paresia de uma das cordas vocaes e em consequencia, palavra um tanto dysarthrica e pouco intelligivel.

As atrophias apresentadas pelo paciente nos parecem ser de origem myelopathica.

Eliminamos a origem nevritica das atrophias, pela falta de reacção de degeneração ao exame electrico, ausencia de dores á pressão no trajecto dos nervos, presença e mesmo vivacidade dos reflexos tendinosos.

A possibilidade de origem myopathica é affastada pela idade do doente, pela falta de antecedentes hereditarios, pelo inicio das atrophias nas extremidades distaes dos membros, assumindo o typo da atrophia Aran-Duchenne e pela presença de contracções de fibrillares.

Ficam affastadas assim as hypotheses de polynevrite e das differentes myopathias.

$\mathrm{O}$ quadro clinico apresentado pelo paciente quando da sua entrada semelhava-se muito ao da esclerose lateral amyotrophica. Praticada a punç̧ão lombar, verificou-se a hyper-albuminose, a hyperlymphocytose, a positividade das reacções de Nonne-Appelt, Pandy, 
Weichbrodt e da reaç̧ão de Wassermann, toda esta syndrome humoral indo de encontro ao diagnostico da molestia descripta por Charcot, sendo portanto esta posta de lado.

Este mesmo exame do liquido cephalo-rachidiano, alliviado á presença de perturbações da sensibilidade, e do exaggero dos reflexos tendinosos afasta o diagnostico de polyomyelite anterior.

Não se pode pensar numa pachymeningite cervical hypertrophica pela ausencia das violentas dores nevralgicas de typo radicular que caracterisa esta molestia.

O diagnostico da esclerose em placas não cabe ao nosso caso pela ausencia, em nosso doente, de tremores intencionaes, palavra escandida e lenta, e de nystagmus, além de que, nesta molestia a reacção de Wassermann no liquido cephalo-rachidiano é negativa, e a reaç̧ão de Guillain é positiva, ao contrario do que se nota no nosso caso.

$\mathrm{O}$ apparecimento posterior de perturbações da sensibilidade superficial nos fazem pensar em lesão dos cordões lateriaes, ou, pelo menos em uma lesão de substancia cinzenta medullar interrompendo ou lesando simplesmente as vias das sensibilidades thermica, dolorosa e tactil. O facto de não haver dissociação syringo-myelica da sensibilidade, e a ausencia concomitante de perturbações trophicas, eliminam a possibilidade da syringo-myelia e da hematomyelia.

A hyper-lymphocytose e hyper-albuminose do liquido cephalorachidiano nos indicam existir um processo inflammatorio das meninges

A reacção de Wassermann positiva no liquido cephalo-rachidiano constitue aqui signal de grande valor para que se possa imputar ao treponema pallido, os symptomas apresentados pelo nosso doente.

A MENINGO-MYELITE SYPHILITICA, nos parece ser a molestia mais amoldavel ao quadro clinico apresentado pelo nosso paciente. A syphilis medullar pode-se localisar nos cornos anteriores e determinar lesões dos cordões lateraes e posteriores, que se traduzem por signaes associados: atrophias musculares, signaes de espasticidade, signal de Babinski, exaggero de reflexos tendinosos e perturbações da sensibilidade.

\section{PROGNOSTICO}

O prognostico é sombrio. Trata-se de uma molestia de origem syphilitica, de evolução rapida em que o tratamento especifico intenso não conseguiu deter a evolução.

Phenomenos bulbares, a principio fructos, taes como dysarthria e paresia de uma corda vocal, manifestam-se agóra com maior nitidez.

E' uma lesão que, localisada inicialmente na medulla, em vez de ahi estacionar, subiu attingindo o bulbo. $\mathrm{O}$ mais das vezes a morte sobrevem pelo comprometimento do pneumogastrico, determinando a parada dos movimentos cardiacos e asphixia por defficiencia respiratoria. 